\title{
Residual risk of transfusion-transmitted malaria infection in a malaria endemic sub-Saharan African setting
}

\author{
Cécile Okalla Ebongue 1,2, Eveline Ngouadjeu Dongho 1,2 ${ }^{1}$ Gaétan Texier ${ }^{3}$, Jean-Pierre Nda Mefo'o $0^{1,2}$, \\ Gerald Sume Etapelong ${ }^{4}$, Lawrence Ayong ${ }^{5}$ and Carole Else Eboumbou Moukoko ${ }^{2,5^{*}}$
}

\begin{abstract}
Background: In Cameroon, as in many malaria endemic countries in Africa, blood donors are not routinely screened for Plasmodium infection that potentially could lead to severe malaria in some recipients. This study aimed at defining the prevalence of malaria among blood donors in Cameroon, and determining the risk of transfusion-transmitted malaria (TTM) following a single unit of blood transfusion.

Methods: A total of 250 blood donors were recruited at the Douala General Hospital in Cameroon. Blood samples were tested for the presence of Plasmodium by using a rapid diagnostic test (RDT), and by thin and thick blood smear microscopy. A mathematical model was performed to calculate individual risk and to estimate population incidence rates of TTM per year. Different data sources were used in the sensitivity analysis prior to estimation of malaria transfusion risk.

Results: More than half (96.8\%) of all blood donors were men, and the mean age of the donors was $28.5(\mathrm{SD}=8.9)$ years. Infected volunteer donors represented $2.80 \%$ while infected family-replacement donors comprised $97.20 \%$. The prevalence of $P$. falciparum infection was $12.0 \%$, and the population mean parasite density was 6,056 (95\% Cl: 4,542-8,076) parasites/ $\mu \mathrm{L}$. The individual median residual risk of TTM was 5.59 per 10,000 or 2.64 per 1,000 units of blood transfused every year in Douala or Cameroon, respectively.

Conclusions: This study confirms the presence of P. falciparum as one of the most prevalent TTls in the region. The residual risk of TTM is high among blood recipients, urging to conduct in malaria-endemic areas a cost-benefit analysis of systematically screening blood units for malaria parasites before transfusion versus systematically treating the recipient after transfusion.
\end{abstract}

Keywords: Blood transfusion, Residual risk, Plasmodium falciparum, Cameroon

\section{Background}

A blood transfusion is needed for severe anemia, an indication of one or more causes, medical, traumatic, surgical, obstetric or pediatric [1]. Blood transfusion is common worldwide and represents a safe therapeutic procedure when performed in compliance with immunological and hygienic standards, as well as following the strict

\footnotetext{
* Correspondence: elsecarole@yahoo.fr; eboumbou@pasteur-yaounde.org ${ }^{2}$ Biological Sciences Unit, Faculty of Medicine and Pharmaceutical Sciences, University of Douala, BP 2701, Douala, Cameroon

${ }^{5}$ Malaria Research Unit, Centre Pasteur of Cameroon, Douala, Cameroon Full list of author information is available at the end of the article
}

screening of donors for transfusion-transmissible infections (TTIs) [1].

Between 1992 and 2002, health services in Cameroon witnessed an exponential rise in blood donors from 75,000 to 130,000 , following the introduction of blood safety guidelines [2]. Despite recent improvements in blood safety in Cameroon following adoption of the 2003 law on blood donation and transfusion [3], the risk of TTI remains high due to the increased demand for blood transfusion. Beside the immunological risk, micro-organisms including bacteria, viruses, and parasites could be transmitted during blood transfusion, and bacterial contamination remains a major potential risk of 
infection during blood transfusion [4-11]. As in many countries worldwide, efforts to minimize blood transfusion risks in Cameroon focus on performing serological tests for human immunodeficiency virus (HIV), hepatitis $\mathrm{B}$ virus (HBV), hepatitis $\mathrm{C}$ virus (HCV), and Treponema pallidum (T. pallidum) due to the fact that these infections are the most feared by patients and prescribers [12-15] and because of the potentially chronic clinical sequelaes associated with these agents [16, 17]. Although recommended by the WHO [12], blood donors are not routinely screened for the detection of Plasmodium infection, which is a treatable infectious disease. This represents a real problem in non-endemic areas where blood recipients may be at increased risk of developing severe malaria due to Plasmodium falciparum ( $P$. falciparum) $[18,19]$. In endemic areas, the risk of symptomatic malaria infection after transfusion is of particular importance in non-immune children, pregnant women and in immunocompromised patients, the reason for which antimalarial treatment is systematically prescribed in some hospitals following blood transfusion [20]. Studies carried out in different African countries have shown that Plasmodium parasites can survive in blood stored at $4{ }^{\circ} \mathrm{C}$ for up to 18 days, and for extended periods when frozen [12, 21]. Thus, some African countries have implemented the obligatory screening of blood units destined for transfusion in pregnant women and young children [6]. In Cameroon, where malaria is endemic, asymptomatic infected blood donors can potentially transmit malaria. However, very few studies have been undertaken to assess the prevalence of malaria infection in blood donors and to investigate the residual risk of TTM in Cameroon and Africa to date $[5,6,22]$. This study aimed to determine the prevalence of malaria, and to estimate the residual malaria risk among blood donors in Cameroon.

\section{Methods}

\section{Study areas and overall study design}

We conducted a cross-sectional study among voluntary and family blood donors attending the blood transfusion center of the Douala general hospital (DGH) over a period of 3 months. The DGH is a reference public health structure with 320 beds, and its blood transfusion center collects over 3500 bags per year that are distributed in all wards of the hospital and other health facilities in the Littoral Region. Blood donors with signs or symptoms associated with any disease, or with a recent history that constitutes a risk for malaria parasite carriage were excluded. Standard questionnaires and data collection sheets were used to collect anthropometric (age, sex, weight), socio-demographic (occupation, place of residence), and clinical (symptoms, blood pressure) and biological data.

\section{Detection of malaria infection and malaria transfusion risk} estimation model

P. falciparum infection was diagnosed by rapid diagnosis tests (RDTs) and microscopic examination of thick and thin blood smears from peripheral venous blood collected in EDTA tubes. The ACON Malaria P falciparum ${ }^{\circ}$ RDT, which detects the $P$. falciparum Histidine Rich Protein 2 (PfHRP-2) was performed according to the manufacturer's instructions using whole blood. The parasitological results were interpreted as positive or negative according to kit instructions. Thick and thin blood smears were performed according to WHO standards [23]. Briefly, $10 \mu \mathrm{L}$ of blood were spread on microscope slides and slides were dried and stained with 5\% Giemsa. Parasite density (expressed in parasites per microliter $(\mathrm{p} / \mu \mathrm{L})$ of blood) was determined by counting the number of asexual parasites against 300 white blood cells with 1 parasite for every 3-4 white blood cells deemed 200 asexual parasites $/ \mu \mathrm{L}$ based on the assumption that the white blood cell count is approximately $8000 / \mu \mathrm{L}$ ). Slides were considered negative when parasites were not detected following examination of microscopy fields containing at least a total of 1000 white blood cells. Parasitemia level $\geq 20 \%$ was chosen as the cutoff because it is the definition of hyperparasitaemia by the WHO (WHO 2000) criteria in an endemic area [24]. When thick films were positive, thin films were read for species determination.

A model proposed by Kane et al., which is based on a generalized simple linear equation, was used to calculate different risk probabilities associated with transmission of bloodborne pathogens [25]. This model allows the calculation of average individual risk in a particular geographical region as well as estimating population incidence of TTIs per year. Data sources provided by the BUCREP (Central Bureau of Census and Population Studies) and the 3rd GPHC (General Population and Household Census) were used to estimate population sizes [26]. In the absence of reliable national and uncertainty data on the number of blood components transfused each year in Cameroon, we used different data sources including WHO, CDC/PEPFAR program, journal articles, and other academic publications to estimate the number of transfused blood units per year [7, 27-29]. Malaria prevalence rates were also obtained from diverse sources [30, 31]. For malaria transmission risk estimation (probability that an infectious blood bag with Plasmodium can be either transmitted to the recipients), we carried out a sensitivity analysis to identify the most contributing input parameters [32].

\section{Statistical analyses of data}

Categorical variables were expressed as frequencies, whereas numerical variables were presented as means +/SDs or $95 \%$ CI (95\% confidence interval instead of), if normally distributed. Parasitemia, a numerical variable 
found to be highly skewed in its distribution, was logtransformed. To compare proportions, we used Chisquare test or Fisher'exact test. Numerical values were compared using the U-test of Wilcoxon. All statistical analyses were done using Stata software package (version $11 \mathrm{SE}$ ) and R software (version 3.1.1) [33]. Only $p$-values $<0.05$ were considered significant in all analyses.

\section{Results}

\section{Characteristics of blood donor population}

For a duration of 3 months in 2011, TTI screening testing was performed on 250 blood donors. The characteristics of the donor groups are compared in Table 1. Seven (2.8\%) blood donors were volunteers whereas 243 (97.2\%) were family-replacement donors. Overall, the prevalence of male donors was $96.8 \%$, and the male/female sex ratio was 30/1. Most of the donors were laborers (47.3\%), with pupils and students representing $30.4 \%$ of all donors. The majority of donors $(68.4 \% ; 171 / 250)$ were less than 31 years old, with the highest frequency recorded in the 21-26 years age group. The mean age of male donors was 28.4 ( $\mathrm{SD}=8.9)$, whereas that of the female donors was $30.2(\mathrm{SD}=7.8)$. None of the donors had previously received a transfusion or a history of fever, malaria or antibiotics drug use within the week before recruitment.

\section{Malaria infection among blood donors and residual transmission risk}

RDT was positive for Plasmodium in 31 (12.4\%) of 250 analyzed blood donors, and 30 of these were also positive by thick blood smear microscopy. $P$ falciparum was the only identified species by thin blood smear. One positive thick blood smear (0.4\%) with Loa loa microfilaria was also found. The parasitemia geometric mean was $6,056.82$ (95\% CI: 4542.0-8076.9) p/ $\mu \mathrm{L}$ and most of $P$. falciparum positive blood donors (87.1\%) had a mean parasitemia $\leq$ $4 \%$. The average parasite carriage per $450 \mathrm{ml}$ donated blood was 3 parasites. The frequency of positive blood donors according to the age group are shown in Fig. 1. It was highest $(25.9 \%)$ in the $15-21$ years age group and decreased thereafter. It was $11.0 \% \%$ among $21-31$ years age group and $4.3 \%$ above 31 years. There was a significant difference $(p=0.002)$ in the frequency of Plasmodium infected blood donors according to age groups.

Malaria transfusion residual risk estimation is presented in Table 2. Regardless of the hypothesis formulated (through the different transmission level: low, medium and high) for the sensitivity analysis, it was estimated that approximately $8,559[5,150-12,838]$ or $69,734[52,396-87,072]$ units of blood were transfused in Douala or Cameroon each year, respectively. Among these, the most likelihood hypothesis is that 1,061 or 20,049 units of blood could be considered contaminated in Douala or Cameroon, respectively. Based on our deterministic model, the individual median risk of acquiring TTM was estimated to be high (5.59 infections per 10,000 and 2.64 per 1,000 units of blood transfused in Douala or Cameroon, respectively). Regardless of our sensitivity analysis, the risk of receiving Plasmodium infected blood unit depended more on the malaria prevalence than the number of transfused blood units.

\section{Co-infection}

At baseline screening, 30 (12.0\%) HBsAg, 2 (0.8\%) anti$\mathrm{HCV}$, and 3 (1.2\%) anti-HIV positive results were recorded. T. pallidum was found in 16 (6.4\%) blood donors. Among the donors, one had a triple infection $(P$. falciparum $+\mathrm{HIV}+T$. pallidum), whereas seven cases of double infection were identified; three for $P$. falciparum + T. pallidum, three for $P$ falciparum $+\mathrm{HBV}$, and one for P. falciparum $+\mathrm{HCV}$.

\section{Discussion}

Malaria parasites are generally recognized risk of blood transfusion in malaria endemic countries worldwide, but

Table 1 Characteristics of blood donors population

\begin{tabular}{|c|c|c|c|c|}
\hline & Volunteers donors & Family-replacement donors & Total & $\mathrm{p}$ \\
\hline Number & $7(2,8)$ & $243(97,2)$ & 250 & \\
\hline Age mean (SD), years & $28,6(6,31)$ & $28,5(8,9)$ & $28,5(8,9)$ & 0,527 \\
\hline Men & $7(100.0)$ & $235(96,7)$ & $242(96,8)$ & 0,238 \\
\hline Thick and thin blood smear & $1(14.3)$ & $29(11.9)$ & $30(12,0)$ & / \\
\hline Parasitemia geometric mean (IC95), parasites/ $\mu$ l & $4500,0(1,0-1,0)$ & $6115,2(4544,0-8234,7)$ & $6056,8(4542,0-8076,9)$ & / \\
\hline \multicolumn{5}{|l|}{ Occupation } \\
\hline Staff members & $1(14,3)$ & $53(21,8)$ & $54(21,6)$ & 0,019 \\
\hline Laborers & $4(57,1)$ & $114(46,9)$ & $118(47,2)$ & \\
\hline Pupils/Students & $2(28,6)$ & $74(30,5)$ & $76(30,4)$ & \\
\hline Unemployement & $0(0,0)$ & $2(0,8)$ & $2(0,8)$ & \\
\hline
\end{tabular}

Data are number and proportion (\%) of blood donors, unless otherwise indicated. Variables were compared by Fischer's exact test (categorical variables) or U-test of Wilcoxon (continuous variables): Statistical significance: $P$-value $<0.05$ 


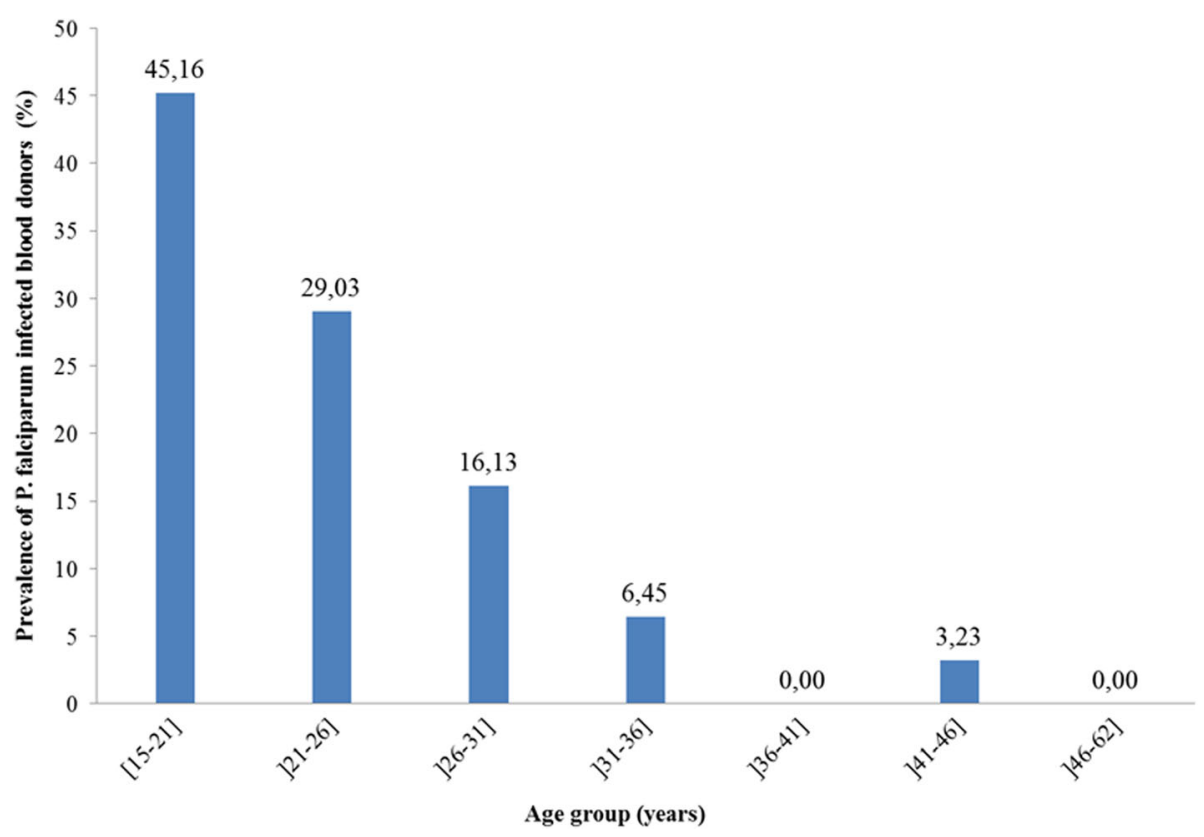

Fig. 1 Distribution of Plasmodium infectious status according to blood donor's age groups

the incidence of TTM remains unknown in many African countries. To our knowledge, this study is the first to investigate the residual risk of TTM in Cameroon, and among the few studies conducted in Africa till date.

During a 3-month high malaria transmission period in Douala, Cameroon, we recruited 250 blood donors at the DGH, with family-replacement donors representing $97.2 \%$ of all blood donors, the majority of whom were male (male/female sex ration of 30:1). Indeed, despite the high blood transfusion needs in sub-Saharan Africa regions, and the increased awareness of its populations, family relatives or acquaintances remain the principal blood donors in the region $[4,8,34-36]$. This is different in Western countries and in North Africa, where blood supply is mainly based on volunteer donation [15, 37, 38]. The trend of high male/female ratio has been reported in other studies in Cameroon [4, 34, 39] and elsewhere [37, 40-42]. This could be explained by physiological factors such as pregnancy, menstruation, and feeding which exclude some women from blood donation.

Blood transfusion practice remains a major challenge in malaria-endemic areas because many potential blood

Table 2 Individual risk of transfusion-transmitted malaria infection according to the transmission level hypothesis (low, medium or high)

\begin{tabular}{|c|c|c|c|c|c|c|}
\hline \multirow[b]{2}{*}{ Variables } & \multicolumn{3}{|l|}{ Douala } & \multicolumn{3}{|l|}{ Cameroon } \\
\hline & Low & Medium & High & Low & Medium & High \\
\hline Population (estimation in 2010) & & 1907479 & & 19406100 & & \\
\hline Estimated proportion of transfusion (u) & 0.0027 & 0.0045 & 0.0067 & 0.0027 & 0.0036 & 0.0045 \\
\hline Estimated $\mathrm{N}^{\circ}$ of transfusion per year & 5,150 & 8,559 & 12,838 & 52,396 & 69,734 & 87,072 \\
\hline Estimated Prevalence among donor- P (vi) & 0.121 & 0.124 & 0.143 & 0.13 & 0.29 & 0.45 \\
\hline Estimated $\mathrm{N}^{\circ}$ of infections per year & 623 & 1,061 & 1,836 & 6,550 & 20,049 & 39,182 \\
\hline $\begin{array}{l}\text { Unsafe transfusion proportion (not screened in an malaria } \\
\text { risk context)-P (u) }\end{array}$ & 0.97 & 0.98 & 0.99 & 0.97 & 0.98 & 0.99 \\
\hline $\begin{array}{l}\text { Probability for exposure to infected blood units-P }(E)=P \\
(\text { vi) })^{* P}(u)\end{array}$ & 0.1173 & 0.1215 & 0.1416 & 0.1212 & 0.2818 & 0.4455 \\
\hline $\begin{array}{l}\text { Probability for malaria transmission following blood } \\
\text { transfusion-P (t) }\end{array}$ & 0.98 & 0.99 & 0.99 & 0.98 & 0.99 & 0.99 \\
\hline Partially immune population & 0 & 0.025 & 0.05 & 0 & 0.025 & 0.05 \\
\hline Probability for recipient susceptibility to malaria-P (s) & 0.95 & 0.975 & 1 & 0.975 & 1 & 0.95 \\
\hline $\begin{array}{l}\text { Individual risk of receiving a transfused infected blood unit } \\
\text { every year-P }(I) ; P(I)=1-\left[1-P(S)^{*} P(t)^{*} P(e)\right] u\end{array}$ & $3.1238 \times 10^{-4}$ & $5.5965 \times 10^{-4}$ & $1.0268 \times 10^{-3}$ & $1.1399 \times 10^{-3}$ & $2.6423 \times 10^{-3}$ & $3.2335 \times 10^{-4}$ \\
\hline
\end{tabular}


donors are infected. Unfortunately, malaria screening is not routinely done in these areas for reasons that include the unavailability of rapid diagnostic tools in local blood banks, and the lack of high performance assays to detect submicroscopic parasite loads in asymptomatic individuals. Our screening of blood donors at the DGH resulted in an incidence rate of $12.0 \%$. This incidence is similar to that found in other countries [29, 43, 44]. It was higher than the $0.7 \%$ in Nairobi a non-endemic area, the $6.5 \%$ in Yaoundé, the $7.8 \%$ in Ibadan, and the $6.5 \%$ in Sudan $[5,29,45-47]$. In contrast to our study, a higher prevalence of malaria was reported during the rainy season in other countries; $26.5 \%$ in Lagos, $33.5 \%$ in Cotonou and over $55 \%$ in highly endemic northern Nigeria [29, 46, 48]. Together, these findings confirm that the prevalence of malaria parasitaemia in African donors depends on the local endemicity and the transmission season $[4,5,29,44,49]$.

$P$ falciparum is the most widespread species in Cameroon [50] and was the only Plasmodium species that was found by RDT and thin smear microscopy in our study. Parasite densities (geometric mean: 6,056.82 $\mathrm{p} / \mu \mathrm{L}$ ) were high and seemed to be sufficient to cause TTM. Indeed, a study conducted in Ghana revealed that the parasite density in blood units that caused TTM was $280 \mathrm{p} / \mu \mathrm{L}$ [49], which could lead to severe and often fatal disease, especially for non-immune recipients [51, 52]. Additionally, a study conducted in a hyperendemic area in Ghana showed that as few as ten parasites are sufficient to initiate fulminant malaria in humans [53], and various studies have reported the detection of $P$. falciparum by PCR or microscopy in some patients soon after blood transfusion despite receiving microscopy-negative blood $[45,49]$. It is worth-noting that microscopy is very less sensitive in asymptomatic malaria cases wherein PCRbased methods are most preferred [45, 49, 54]. Together, these findings suggest that despite the absence of clinical signs, donors living in endemic areas are very likely to transmit malaria through blood transfusion.

By including estimates of blood recipient population, the risks of TTI in screened or unscreened blood units, and by conducting probabilistic sensitivity analysis, we estimated that the median risk of acquiring $P$. falciparum from a single unit of blood in Douala or Cameroon is 5.59 infections per 10,000 or 2.64 infections per 1,000 units of transfused blood, respectively. Regardless of our sensitivity analysis, the risk of receiving Plasmodium infected blood unit depends more on the malaria prevalence than the number of transfused blood units. Transfusions alone would be responsible for 1,061 and 20,049 malaria infections respectively in Douala or Cameroon each year.

The proposed Kane model takes into account the immunity or semi-immunity of the donors, and therefore a variable sensitivity to infection, and a partial infectivity to any pathogen [25]. The data on infectivity are difficult to access, and the few available data cannot be applied to all countries given the differences in malaria transmission endemicity levels. We used different values covering a wide range of prevalence (low and high hypothesis) in Cameroon by using the sensitivity analysis. Probabilistic sensitivity analysis indicates that the true risks may even be higher considering the number of individuals with low and undetectable blood parasitaemia, and the ability of these parasites to remain viable for long periods in stored blood units [12, 21].

A review of studies conducted in sub-Saharan Africa indicates that malaria is one of the most significant posttransfusional infections [29]. The risk is quite real, and this high residual risk of malaria raises once again two major concerns with respect to blood safety in malaria endemic areas: i) the introduction of systematic RDTbased screening and destruction of infected blood units as clinical criteria remains unreliable [55-57], or ii) the systematic provision of anti-malarial prophylaxis to blood recipients as recommended by the WHO and other stakeholders [58-61]. Eliminating all Plasmodium infected blood units is however inconceivable as many patients do not have access to blood when needed; $38 \%$ of the estimated 80 million units of annually donated blood worldwide come from the developing world [58]. Which of the 1st or the 2nd strategies is the most cost-effective to lessen the risk of TTM in sub-Saharan Africa? Some possible answers are presented in the review by Nansseu et al. [62]. In either case, there is an urgent need to conduct cost-benefit studies to evaluate each of these two TTM preventive methods. In our context, Plasmodium positive blood units could be transfused under cover of appropriate and effective malaria treatment of recipients, particularly for fragile subjects (neonates, pregnant women).

\section{Limitations and strengths}

A limitation of this study was in the small sample size of donors $(n=250)$ and the non-use of PCR to detect submicroscopic malaria. Compared to previous reports, our study is the first to investigate the residual risk of TTM in Cameroon. Although our findings clearly cannot be applied to all regions, this work has important implications for understanding the burden of malaria that may be attributable to contaminated blood products in Cameroon.

\section{Conclusions}

This study confirms the presence of TTIs in blood donors at the DGH in Cameroon, identifying P. falciparum as one of the most prevalent TTIs in the region. Our findings suggest a high risk of TTM among blood recipients in malaria endemic countries, requiring the implementation 
of appropriate preventive measures such as systematic pre-screening of blood donors or systematic anti-malarial prophylaxis to blood recipients in high-risk populations. A comparative cost-benefit analysis is however needed to identify the most efficient preventive strategy for each affected region.

\section{Abbreviations}

BUCREP: Bureau Central de Recensement et des Etudes de Population/Central Bureau of Census and Population Studies; CDC: Centers for disease control and prevention; Cl: Confidence interval; DGH: Douala General Hospital; GPHC: General Population and Household census; HBV: Hepatitis B virus; HCV: Hepatitis C virus; HIV: Human immunodeficiency virus; PEPFAR: President's Emergency Plan for AIDS Relief; PfHRP-2: P. falciparum Histidine Rich Protein 2; RDT: Rapid diagnostic test; T. pallidum: Treponema pallidum; TTIs: Transfusiontransmissible infections; TTM: Transfusion-transmitted malaria; WHO: World Health Organization

\section{Acknowledgements}

We are very grateful to the blood donors who agreed to participate in this study. We express our gratitude to the staff of the Laboratory of clinical biology of the DGH for their support and cooperation during the survey. Thanks to Eboumbou M. who reviewed and revised the manuscript for language editing. This work was supported by the DGH and the International Society for Health Research and Training (ISRT-Health).

\section{Funding}

Statistical analysis and the interpretation of data were financially supported by the International Society for Health Research and Training (ISRT-Health), a local Lecturer network.

\section{Availability of data and materials}

All data supporting these findings can be found in the blood transfusion center of the clinical biology unit of the DGH, a reference public health structure located in Douala, Cameroon. Data could not be shared, they are the property of the hospital which is only to decide their disclosure or not.

\section{Authors' contributions}

COE and CEEM coordinated the study and drafted the manuscript. COE, END and JPNM collected data and participated in its design. COE, GT and CEEM performed the statistical analysis. All authors read and approved the final manuscript.

\section{Competing interests}

The authors declare that they have no competing interests.

\section{Consent for publication}

Consent to publish has been obtained from all included persons in the study.

\section{Ethics approval and consent to participate}

This study was conducted in accordance with ethics directives related to research on humans in Cameroon. The DGH institutional review board approved the study. Before enrollment, subjects were informed on the purpose and process of the investigation (goals, methodology, study constraints, data confidentiality, and rights to opt out from the study), and an oral informed consent was obtained from all participants.

\section{Publisher's note}

Springer Nature remains neutral with regard to jurisdictional claims in published maps and institutional affiliations.

\section{Author details}

${ }^{1}$ Laboratory of Clinical Biology, Douala General Hospital, Douala, Cameroon. ${ }^{2}$ Biological Sciences Unit, Faculty of Medicine and Pharmaceutical Sciences, University of Douala, BP 2701, Douala, Cameroon. ${ }^{3}$ UMR912-SESSTIM-INSERM/ IRD/Aix-Marseille, Faculté de Médecine, Marseille, France. ${ }^{4}$ Regional Delegation of Public Health, Douala, Cameroon. ${ }^{5}$ Malaria Research Unit, Centre Pasteur of Cameroon, Douala, Cameroon.
Received: 21 October 2016 Accepted: 3 March 2017

Published online: 11 March 2017

\section{References}

1. WHO (World Health Organization). The clinical use of blood. WHO. http://www who.int/bloodsafety/clinical_use/en/Manual_EN.pdf. Accessed 2 Feb 2017.

2. ANRS. Historical and anthropological approaches to blood transfusion in Cameroun and Ouganda. ANRS Project 12196. 2012. (French version only). http://www.anrs.fr/content/download/2954/16845/file/36_Mbanya.pp.s. Accessed 15 Sept 2014.

3. Cameroon Prime Minister's Office: Legislation and regulations. Law No. 2003/014 of 22 December, 2003 relating to blood transfusion. Laws and statutory instruments (French version only) 2003. http://www.spm.gov. $\mathrm{cm} / \mathrm{fr} /$ documentation/textes-legislatifs-et-reglementaires/article/loi-n2003014-du-22-decembre-2003-portant-sur-la-transfusion-sanguine.html. Accessed 15 Jul 2014.

4. Noubiap JJ, Joko WY, Nansseu JR, Tene UG, Siaka C. Sero-epidemiology of human immunodeficiency virus, hepatitis $B$ and $C$ viruses, and syphilis infections among first-time blood donors in Edéa, Cameroon. Int J Infect Dis. 2013:17(10):e832-7.

5. Noubouossie D, Tagny CT, Same-Ekobo A, Mbanya D. Asymptomatic carriage of malaria parasites in blood donors in Yaoundé. Transfusion Med. 2012;22:63-7

6. El Ghouzzi ME, Garraud O. Parasites et transfusion sanguine: causes et conséquences. Hematol. 2006;12:129-39.

7. Mbanya D, Binam F, Kaptue L. Transfusion outcome in a resource-limited setting of Cameroon: A 5-year evaluation. Int J Infect Dis. 2001;5(2):70-3.

8. Eboumbou Moukoko EC, Ngo Sack F, Essangui Same GE, Mbangue M, Lehman GL. HIV, HBV, HCV and T. pallidum infections among blood donors and Transfusion-related complications among recipients at the Laquintinie hospital in Douala, Cameroon. BMC Hematol. 2014;14(1):5-9.

9. Baidy L, Abdalay D, Sow A. Séroprévalence tréponémique chez les donneurs de sang au centre hospitalier national de Nouakchott (Mauritanie). Med Afr Noire. 1998;45(8/9):511-3.

10. Noah Noah D, Njouom R, Bonny A, Pirsou P, Meli J, Biwole Sida M. HBs antigene prevalence in blood donors and the risk of transfusion of hepatitis $B$ at the central hospital of Yaounde, Cameroon. Open J Gastroenterol. 2011;1:23-7.

11. Liu J, Huang Y, Wang J, Guo N, Li J, Dong X, Ma H, Tiemuer M, Huang M, Wright DJ, Ness P, Shan $H$. The increasing prevalence of serologic markers for syphilis among Chinese blood donors in 2008 through 2010 during a syphilis epidemic. Transfusion. 2012;52:1741-9.

12. WHO (World Health Organization). Screening donated blood for transfusiontransmissible infections: recommendations. WHO Genève. 2010. (French version). http://apps.who.int/iris/bitstream/10665/112663/1/9789242547887 fre.pdf. Accessed 15 Jul 2015.

13. Ministry of Public Health in Cameroon, National AIDS Control Committee, Central Technical Group. National HIV/AIDS Control Strategic Plan, 2006-2010. http://www.cnls.cm/docs/psn/NSP\%202006-2010_uk.pdf. Accessed 15 July 2015.

14. Lucky TT, Seed CR, Keller A, Lee J, McDonald A, Ismay S, Wand H, Wilson DP. Trends in transfusion-transmissible infections among Australian blood donors from 2005 to 2010. Transfusion. 2013;53(11):2751-62.

15. Pillonel JET, Laperche S. Surveillance épidémiologique des donneurs de sang homologues et risque résiduel en France entre 2003 et 2005: Bilans réguliers de surveillance. Bull Epidemiol Hebd. 2006;51:411-4.

16. Kaur $P$, Basu S. Transfusion-transmitted infections: existing and emerging pathogens. J Postgrad Med. 2005;51(2):146-51.

17. Bihl F, Castelli D, Marincola F, Dodd RY, Brander C. Transfusion-transmitted infections. J Transl Med. 2007:5:25-35.

18. Danis M, Legros F, Thellier M, Caumes E. Current data on malaria in metropolitan France. Med Trop. 2002;62:214-8.

19. Mungai M, Tegtmeier G, Chamberland M, Parise M. Transfusion-transmitted malaria in the United States from 1963 through 1999. N Engl J Med. 2001;344:1973-8.

20. Nansseu JR, Alima Yanda AN, Chelo D, Tatah SA, Mbassi Awa HD, Seungue J, Koki PO. The Acute Chest Syndrome in Cameroonian children living with sickle cell disease. BMC Pediatr. 2015;15(1):131-8.

21. Chattopadhyay R, Majam VF, Kumar S. Survival of Plasmodium falciparum in human blood during refrigeration. Transfusion. 2011;51:630-5.

22. Tagny $C T$, Mbanya D, Garraud $O$, Lefrère JJ. Blood safety: malaria and blood donation in Africa. Transfus Clin Biol. 2007;14:481-6. 
23. WHO (World Health Organization). Basic laboratory methods in medical parasitology. WHO. 1993; 71p. (French version). http://apps.who.int/iris/ bitstream/10665/37025/1/9242544108_\%28part1\%29.pdf. Accessed 17 Apr 2016.

24. WHO (World Health Organization). Severe falciparum malaria: World Health Organization, Communicable Diseases Cluster. Trans R Soc Trop Med Hyg. 2000;94(1):S1-S90.

25. Kane A, Lloyd J, Zaffran M, Simonsen L, Kane M. Transmission of hepatitis B, hepatitis $C$ and human immunodeficiency viruses through unsafe injections in the developing world: model-based regional estimates. B World Health Organ. 1999;77(10):801-7.

26. BUCREP (Central Bureau of the Census and Population Studies). Résultats du 3ème RGPH: Projections Démographiques, Rapports National sur l'Etat de la Population. http://www.bucrep.cm/index.php/en/. Accessed 17 Aug 2015.

27. Tapko JB, Toure B, Sambo LG. Status of Blood Safety in the WHO African Region: Report of the 2010 Survey. WHO Regional Office for Africa 2014: 55p. http://www.afro.who.int/index.php?option=com_docman\&task=doc_ download\&gid=9135\&ltemid=2593. Accessed 17 Aug 2015.

28. WHO (World Health Organization). Committee on International Relations Subcommittee on Africa, Global Human Rights and International Operations U.S. House of Representatives. Making Safe Blood Available in Africa. WHO 2006; p. 7. http://www.who.int/bloodsafety/makingsafebloodavailableinafrica statement.pdf?ua=1. Accessed 17 Apr 2015.

29. Owusu-Ofori AK, Parry C, Bates I. Transfusion-transmitted malaria in countries where malaria is endemic: a review of the literature from Sub-Saharan Africa. Clin Infect Dis. 2010;51:1192-8.

30. NMCP (National Program to Fight Against Malaria in Cameroon). Activities Report. NMCP. 2012. p. 50. French version only.

31. Institut National de la Statistique, Ministère de l'Économie de la Planification et de l'Aménagement du Territoire, Ministère de la Santé Publique et Inner City Fund (ICF) International, Calverton, Maryland, USA. The Demographic and Health Survey (DHS) program-Cameroon: 2011; Final Report (French version only). EDS-MICS. 2012; 576p. http://dhsprogram.com/publications/ publication-fr260-dhs-final-reports.cfm. Accessed 17 Nov 2015.

32. Iman RL, Helton JC. An Investigation of Uncertainty and Sensitivity Analysis Techniques for Computer Models. Risk Anal. 1988;8(1):71-90.

33. R Core Team. R. A language and environment for statistical computing. $\mathrm{R}$ Foundation for Statistical Computing, Vienna, Austria. ISBN 3-900051-07-0. http://www.R-project.org/. Accessed 17 Nov 2015.

34. Koangan Mogtomo ML, Louandji Fomekong S, Fotso Kuate H, Ngono NA. Détection des agents infectieux dans les banques de sang de Douala (1995-2004). Cahiers d'études et de recherches francophones/Santé. 2009:19:3-8.

35. Rolseth S, Stange P, Adamou D, Roald B, Danki-Sillong F, Jourdan P. The acceptability of volunteer, repeat blood donations in a hospital setting in the Adamaoua region of Cameroon. Transfus Med. 2014;24(6):372-8.

36. Mecky In M, Pius MM, Eligius FL. Seroprevalence of human immunodeficiency virus, hepatitis B and C viruses and syphilis infections among blood donors at the Muhimbili National Hospital in Dar Es Salaam, Tanzania. BMC Public Health. 2006;6:21-6.

37. Uzun B, Güngör S, Demirci M. Seroprevalence of transfusion transmissible infections among blood donors in western part of Turkey: A 6-year study. Transfus Apher Sci. 2013;49(3):511-5.

38. Acar A, Kemahli S, Altunay H, Kosan E, Oncul O, Gorenek L, Cavuslu S. HBV, HCV and HIV seroprevalence among blood donors in Istanbul, Turkey: how effective are the changes in the national blood transfusion policies? Braz J Infect Dis. 2010;14(1):41-6.

39. Zekeng $\mathrm{L}$, Kaptuen L. Sérologie $\mathrm{VIH}$ et portage de l'antigène HBs et Hbe chez les donneurs de sang au CHU de Yaoundé, Cameroun. Ann Soc Belgium Med Trop. 1990;70:49-53.

40. Naheed A, Jawad A, Nazish A, Jehan F, Saleem S. Transfusion transmitted malaria in three major blood banks of Peshawar, Pakistan. Afr J Biotechnol. 2010;9:5445-9.

41. Uneke CJ, Ogbu O, Nwojiji V. Potential risk of induced malaria by blood transfusion in South-Eastern Nigeria. McGill J Med. 2006;9:8-13.

42. Hoque MM, Islam MA, Begum HA, Rahman M, Rahman SM, Al Mamum MA, Chowdury FS, Hossain MA. Prevalence of malaria parasites among blood donors in selected hospitals of Dhaka City. J Dhaka Med Coll. 2008;17:94-7.

43. Pondei K, Lawani E, Ndiok E. Prevalence of the malaria parasite in screened blood in a tertiary health centre in the malaria-endemic Niger Delta region of Nigeria. Glo Adv Res J Microbiol. 2012;1:188-93.
44. Erhabor O, OK O, Awah I, Uko KE, Charles AT. The prevalence of plasmodia parasiraemia among donors in the Niger delta of Nigeria. Trop Doct. 2007;37:32-4.

45. Ali MS, Yousif AG, Mustafa MS, Ibrahim MH. Evaluation of malaria parasite screening procedures among Sudanese blood donors. Clin Lab Sci. 2005;18(2):69-73.

46. Kinde-Gazard J, Oke I, Gnahoui I, Massougbodji A. Le risque de paludisme transfusionnel à Cotonou. Cahiers d'étude et de recherches francophones/ Santé. 2000;10:389-90.

47. Akinboye DO, Ogunrinade AF. Malaria and loaisis among blood donors at Ibadan, Nigeria. Trans R Soc Trop Med Hyg. 1987;81:398-9.

48. Agboola TF, Ajayi MB, Adeleke MA, Gyang PV. Prevalence of malaria parasite among blood donors in Lagos University teaching hospital, Lagos Nigeria. Ann Biol Res. 2010;1:72-5.

49. Owusu-Ofori AK, Betson M, Parry CM, Stothard JR, Bates I. Transfusion transmitted malaria in Ghana. Clin Infect Dis. 2013;56:1735-41.

50. MPH (Ministry of Public Health). National Strategic Plan for the Fight against Malaria 2011-2015. 2012. p. 94. French version only.

51. Diop S, Ndiaye M, Seck M, Chevalier B, Jambou R, Sarr A, Dièye TN, Touré AO, Thiam D, Diakhaté L. Prevention of transfusion transmitted malaria in endemic area. Transfus Clin Biol. 2009;16:454-9. French version only.

52. Vareil MO, Tandonnet $O$, Chemoul A, Bogreau H, Saint-Léger M, Micheau M, Millet P, Koeck JL, Boyer A, Rogier C, Malvy D. Unusual transmission of Plasmodium falciparum, Bordeaux, France, 2009. Emerg Infect Dis. $2011 ; 17: 248-50$.

53. Freimanis $G$, Sedegah $M$, Owusu-Ofori $S$, Kumar S, Allain JP. Investigating the prevalence of transfusion transmission of plasmodium within a hyperendemic blood donation system. Transfusion. 2013;53:1429-41.

54. Ganguly S, Saha P, Guha SK, Biswas A, Das S, Kundu PK, Maji AK. High prevalence of asymptomatic malaria in a tribal population in eastern India. J Clin Microbiol. 2013;51(5):1439-44.

55. Kitchen AD, Chiodini PL. Malaria and blood transfusion. Vox Sang. 2006;90:77-84

56. Atchade PS, Doderer-Lang C, Chabi N, Perrotey S, Abdelrahman T, Akpovi CD, Anani L, Bigot A, Sanni A, Candolfi E. Is a plasmodium lactate dehydrogenase (pLDH) enzyme-linked immunosorbent (ELISA)-based assay a valid tool for detecting risky malaria blood donations in Africa? Malar J. 2013;12:279-87.

57. Falade CO, Nash O, Akingbola TS, Michael OS, Olojede F, Ademowo OG. Blood banking in a malaria-endemic area: evaluating the problem posed by malarial parasitaemias. Ann Trop Med Parasitol. 2008;103:383-92.

58. WHO (World Health Organization). World Malaria Report. WHO. 2012. www. who.int/iris/bitstream/10665/78945/1/9789241564533_eng.pdf?ua=1. Accessed 12 Nov 2015.

59. WHO (World Health Organization). Department of Essential Health Technologies: Blood Transfusion Safety. WHO. 2011; 6p. https://www.google. fr/?gws_rd=ssl\#q=Department+of+Essential+Health+Technologies:+Blood +Transfusion+Safety. Accessed 12 Nov 2014

60. Seed CR, Kee G, Wong T, Law M, Ismay S. Assessing the safety and efficacy of a test-based, targeted donor screening strategy to minimize transfusion transmitted malaria. Vox Sang. 2010;98(1):e182-92.

61. WHO (World Health Organization). The Africa Malaria Report 2003. WHO. 2003. http://apps.who.int/iris/bitstream/10665/67869/1/WHO_CDS_MAL_ 2003.1093.pdf. Accessed 12 Nov 2015.

62. Nansseu JR, Noubiap JJ, Ndoula ST, Zeh AF, Monamele CG. What is the best strategy for the prevention of transfusion-transmitted malaria in sub-Saharan African countries where malaria is endemic? Malar J. 2013;12:465-73. 